\title{
Short communication: Tryptic $\beta$-casein hydrolysate modulates enteric nervous system development in primary culture
}

\author{
F. Cossais, ${ }^{1,2}$ I. Clawin-Rädecker, P. C. Lorenzen, and M. Klempt \\ Department of Safety and Quality of Milk and Fish Products, Max-Rubner-Institut, 24103 Kiel, Germany
}

\begin{abstract}
The intestinal tract of the newborn is particularly sensitive to gastrointestinal disorders, such as infantile diarrhea or necrotizing colitis. Perinatal development of the gut also encompasses the maturation of the enteric nervous system (ENS), a main regulator of intestinal motility and barrier functions. It was recently shown that ENS maturation can be enhanced by nutritional factors to improve intestinal maturation. Bioactivity of milk proteins is often latent, requiring the release of bioactive peptides from inactive native proteins. Several casein-derived hydrolysates presenting immunomodulatory properties have been described recently. Furthermore, accumulating data indicate that milk-derived hydrolysate can enhance gut maturation and enrichment of milk formula with such hydrolysates has recently been proposed. However, the capability of milk-derived bioactive hydrolysate to target ENS maturation has not been analyzed so far. We, therefore, investigated the potential of a recently described tryptic $\beta$-casein hydrolysate to modulate ENS growth parameters in an in vitro model of rat primary culture of ENS. Rat primary cultures of ENS were incubated with a bioactive tryptic $\beta$-casein hydrolysate and compared with untreated controls or to cultures treated with native $\beta$-casein or a Prolyve $\beta$-casein hydrolysate (Lyven, Colombelles, France). Differentiation of enteric neurons and enteric glial cells, and establishment of enteric neural network were analyzed using immunohistochemistry and quantitative PCR. Effect of tryptic $\beta$-casein hydrolysate on bone morphogenetic proteins (BMP)/Smad pathway, an essential regulator of ENS development, was further assessed using quantitative PCR and immunochemistry. Tryptic $\beta$-casein hydrolysate stimulated neurite outgrowth and simultaneously modulated the formation of enteric ganglia-like struc-
\end{abstract}

Received May 11, 2016.

Accepted January 5, 2017.

${ }^{1}$ Current address: Institute of Anatomy, Christian-AlbrechtsUniversity of Kiel, 24118 Kiel, Germany.

${ }^{2}$ Corresponding author: f.cossais@anat.uni-kiel.de tures, whereas native $\beta$-casein or Prolyve $\beta$-casein hydrolysate did not. Additionally, treatment with tryptic bioactive $\beta$-casein hydrolysate increased the expression of the glial marker glial fibrillary acidic protein and induced profound modifications of enteric glial cells morphology. Finally, expression of BMP2 and BMP4 and activation of Smad1/5 was altered after treatment with tryptic bioactive $\beta$-casein hydrolysate. Our data suggests that this milk-derived bioactive hydrolysate modulates ENS maturation through the regulation of BMP/Smad-signaling pathway. This study supports the need for further investigation on the influence of milk-derived bioactive peptides on ENS and intestinal maturation in vivo.

Key words: milk-derived bioactive peptide, enteric nervous system, bone morphogenetic proteins, neurotrophic

\section{Short Communication}

During the first weeks of life, dramatic maturational changes occur in the intestine of the newborn. Impairment of this process may lead to the development of important gastrointestinal disorders in infants, such as infantile diarrhea or necrotizing colitis, or increased risks of developing intestinal inflammatory disorders later in life, such as in inflammatory bowel diseases. Within the intestinal tract, the enteric nervous system (ENS) is a main regulator of intestinal motility and barrier functions (Neunlist et al., 2013; Furness, 2012). Maturation of the ENS is characterized by the acquisition of a differentiated phenotype by enteric neurons (de Vries et al., 2010) and enteric glial cells (EGC; Cossais et al., 2016) and represents an essential step for the establishment of enteric functions (de Vries et al., 2010).

Although in part regulated by genetic factors, such as members of the bone morphogenetic proteins (BMP) 2 and 4 (Chalazonitis and Kessler, 2012), it was recently shown that ENS maturation can be enhanced by nutritional factors, including milk-derived factors. This highlights the potential to target the ENS to improve intestinal maturation (Fichter et al., 2011; Suply et al., 2012). 
Many peptides generated by the proteolysis of milk proteins demonstrate biological activities, which are not observable with the undigested native proteins (Meisel, 2005). Interest for such bioactive peptides has rapidly grown in the recent years, and supplementation of formula with bioactive milk-derived hydrolysate was recently proposed (Lönnerdal, 2014; Raikos and Dassios, 2014). However, capability of such hydrolysates to target ENS maturation has never been investigated. Therefore, we analyzed the potential of a recently characterized bovine tryptic $\beta-\mathrm{CN}$ hydrolysate presenting anti-inflammatory properties (Altmann et al., 2016) to nutritionally target ENS development.

A detailed protocol for the production of native $\beta$-CN and tryptic bioactive $\beta$-CN hydrolysate ( $\mathrm{T}$ hydrolysate) has been previously published (Altmann et al., 2016). In brief, $\alpha_{S^{-}}$and para- $\kappa-C N$ were precipitated and filtered from a $5 \%$ rennet casein solution (wt/wt; Fonterra, Auckland, New Zealand). $\beta$-Casein was precipitated by slowly warming the remaining solution to $40^{\circ} \mathrm{C}$. $\beta$-Casein precipitate was collected and further solubilized in demineralized water by adjusting the $\mathrm{pH}$ to $7.0\left(25^{\circ} \mathrm{C}\right)$ before lyophilization. The $\beta-\mathrm{CN}$ lyophilisate was composed of 83 to $85 \% \beta-\mathrm{CN}$, whereas the remaining $15 \%$ were composed essentially of $\kappa-\mathrm{CN}$ and other minor milk contents (determined by PAGE). Tryptic proteolysis of the obtained $\beta-\mathrm{CN}$ was performed and the proteolysate was fractionated by ultrafiltration using a membrane with a cutoff of $5 \mathrm{kDa}$. The 5 -kDa retentate was used as bioactive hydrolysate (T-hydrolysate) in our study. In parallel, the $\beta-\mathrm{CN}$ lyophilisate was hydrolyzed with the serine alkaline protease Prolyve 1000 (Lyven, Colombelles, France), added at an enzyme-to-substrate-ratio of $30 \mathrm{U} / \mathrm{g}$ of $\beta$-CN to generate a control hydrolysate (P-hydrolysate) presenting a largely distinct peptide profile than the T-hydrolysate [Figure 1 and Table 1; see Altmann et al. (2016) for a detailed description of the T-hydrolysate). Proteolysis was performed at $50^{\circ} \mathrm{C}$ for $4 \mathrm{~h}$ while the $\mathrm{pH}$ was kept constant with $\mathrm{NaOH}$ at 7.0. The reaction was stopped by heating to $90^{\circ} \mathrm{C}$ for $10 \mathrm{~min}$. This Prolyve proteolysate was fractionated by ultrafiltration at $40^{\circ} \mathrm{C}$ using a membrane with a nominal molecular weight cut-off of $5 \mathrm{kDa}$. The generated peptides were separated and identified by online HPLC coupled to an electrospray ionization mass spectrometry (HPLC-ESI$\mathrm{MS}^{\mathrm{n}}$ ) using an ion trap mass spectrometer LTQ XL (Thermo Scientific Inc., San Jose, CA). Freeze-dried Prolyve proteolysates were dissolved in $0.1 \%$ (vol/vol) formic acid and analyzed on a reversed phase column (Hypersil Gold aQ, $3 \mu \mathrm{m}, 150 \times 2.1 \mathrm{~mm}$, Thermo Scientific Inc.). Solvents used for the chromatographic separation were $0.1 \%$ (vol/vol) formic acid in ultrapure water (solvent A) or $0.1 \%$ (vol/vol) formic acid in acetonitrile (solvent B). A linear gradient from 3 to $60 \%$ solvent B was applied over $40 \mathrm{~min}$ at a flow rate of $0.2 \mathrm{~mL} / \mathrm{min}$, followed by a column wash step with $90 \%$ solvent $\mathrm{B}$ for $5 \mathrm{~min}$ and re-equilibrating at the initial conditions for at least $10 \mathrm{~min}$.

Mass spectra were generated in the positive ionization mode in the full scan range (220 up to $2,000 \mathrm{~m} / \mathrm{z}$ ) and with a data-dependent scan with fragmentation of the 5 most intense ions (activation type $=$ collisioninduced dissociation, normalized collision energy = $35.0 \mathrm{eV}$, isolation width of 2 , and an activation radio frequency of 0.250). Electrospray ionization voltage was set to $3.5 \mathrm{kV}$; capillary temperature was $275^{\circ} \mathrm{C}$. Data acquisition and processing was performed with Xcalibur version 2.0.7 SP1 (Thermo Scientific Inc.). Peptide sequences were identified by Bos taurusrestricted database searches (http://www.uniprot.org/ uniprot/?query=reviewed:yes taxonomy:9913) with Proteome Discoverer 1.4 (Thermo Scientific Inc.) using the search algorithm SEQUEST and MASCOT.

Animal husbandry and ENS primary cultures were performed according to Chevalier et al. (2008) with minor adaptations. Procedures were approved by the ministry of Energy, Agriculture, Environment and Rural Areas of Schleswig Holstein (Kiel, Germany; agreement V312-7224.123-5). Briefly, whole intestine was collected from Sprague-Dawley rat embryos at 15.5 d old (embryonic age; Charles River, Sulzfeld, Germany). Intestines from 1 litter (7-14 embryos) were pooled together and represent 1 batch of culture. All experiments were performed on at least 3 independent batches of culture. Tissues were finely diced in PBS and further digested at $37^{\circ} \mathrm{C}$ for 15 min with $0.1 \%$ trypsin in Dulbecco's modified Eagle's medium-F12 medium (50/50, PAN-Biotech, Aidenbach, Germany) containing $100 \mathrm{U} / \mathrm{mL}$ of penicillin and $100 \mu \mathrm{g} / \mathrm{mL}$ of streptomycin (PAN-Biotech). Tissues were then treated with $0.01 \%$ DNaseI (Sigma-Aldrich, Munich, Germany) for $10 \mathrm{~min}$ at $37^{\circ} \mathrm{C}$. After homogenization, cells were centrifuged at $100 \times g$ at $4^{\circ} \mathrm{C}$ for $10 \mathrm{~min}$, and seeded in gelatin-coated 24-wells plates (Corning Inc., Kaiserslautern, Germany) or in removable 12-well Chamber (Ibidi, Martinsried, Germany) and cultured in a humidified $5 \% \mathrm{CO}_{2}-95 \%$ air incubator at $37^{\circ} \mathrm{C}$. After $24 \mathrm{~h}$, considered d 1, the medium was replaced by Dulbecco's modified Eagle's medium-F12 containing $100 \mathrm{U} / \mathrm{mL}$ of penicillin, $100 \mu \mathrm{g} / \mathrm{mL}$ of streptomycin, and $1 \%$ of N-2 supplement (N-2 medium, Pan-Biotech). At d 2, ENS cultures were treated with T-hydrolysate, P-hydrolysate, or $\beta$-CN (each $1 \mathrm{mg} / \mathrm{mL}$ ) diluted in $\mathrm{N}-2$ medium or left untreated (control) for further 48 to $96 \mathrm{~h}$ before analysis. Control, $\beta$-CN-, or hydrolysates- 
supplemented medium was renewed after $48 \mathrm{~h}$. The concentration of $1 \mathrm{mg} / \mathrm{mL}$ was chosen based on previous publications and preliminary results (Malinowski et al., 2014; Altmann et al., 2016).

Immunocytochemistry was performed as published before (Krüger et al., 2014). After the indicated time, cells were fixed with $4 \%$ formaldehyde, immunostained for the neuronal markers NF165 (mouse monoclonal, 1/5,000, Developmental Studies Hybridoma Bank, Iowa City, IA) or HuC/D (mouse monoclonal, 1/1,000, Life Technologies, Karlsruhe, Germany), the glial marker S100ß (rabbit polyclonal, 1/1,000, Dako, Hamburg, Germany), and for phospho-Smad1/5 (rabbit, 1/500, Life Technologies) and visualized with secondary antibodies donkey anti-mouse Alexa488 (1/200, Life Technologies) and donkey anti-rabbit Cy3 (1/500, Jackson ImmunoResearch, Suffolk, UK). Pictures were acquired with an AxioCam MRc digital camera coupled to an Axioskop2 plus right microscope (Zeiss, Oberkochen, Germany) or a DFC 365 FX digital camera coupled to an SP8 inversed microscope (Leica, Wetzlar, Germany). Cell counting, area, and signal intensity measurements, were performed using the ImageJ software (National Institutes of Health, Bethesda, MD).
For mRNA expression analysis, mRNA was isolated using Crystal RNA mini kit (Biolab Products, Bebensee, Germany) according to manufacturer's recommendations. Synthesis of cDNA and quantitative PCR were performed as described earlier (Krüger et al., 2014). Relative expression to control was determined using the $\Delta \Delta \mathrm{Ct}$ (cycle threshold) method using the ribosomal protein S6 (RPS6, NM_017160) as reference, with the following primer pairs used: CCAAGCTTATTCAGCGTCTTGTTACTCC and CCCTCGAGTCCTTCATTCTCTTGGC for RPS6; CCTGGAACAGCAAAACAAGG and AGCCTCAGGTTGGTTTCATC for glial fibrillary acidic protein (NM_017009); GAGCTGGAGAAGGCCATGG and CTAATCTCACTCATGTTCAAAGAACTC for S100 $\beta$ (NM_013191); CACGAGAATGGACGTGCCC and GGGGAAGCAGCAACACTAGAA for BMP2 (NM_017178); GAAGAAGAGCAGAGCCAGGGAACC and CCGAAATAGCCGGAGCTCTGCAG for BMP4 (NM_012827); GTGAAAAAGTGGCTGTCAAAGTA and AACTTGAGTAGGGCTCTGGT for BMP receptor Ia (NM_030849); AGACCTCGGTACAGCATTGG and ACCTTTTCTCCACGCCACTT for BMPrIb (NM_001024259); and CTACGGCT-

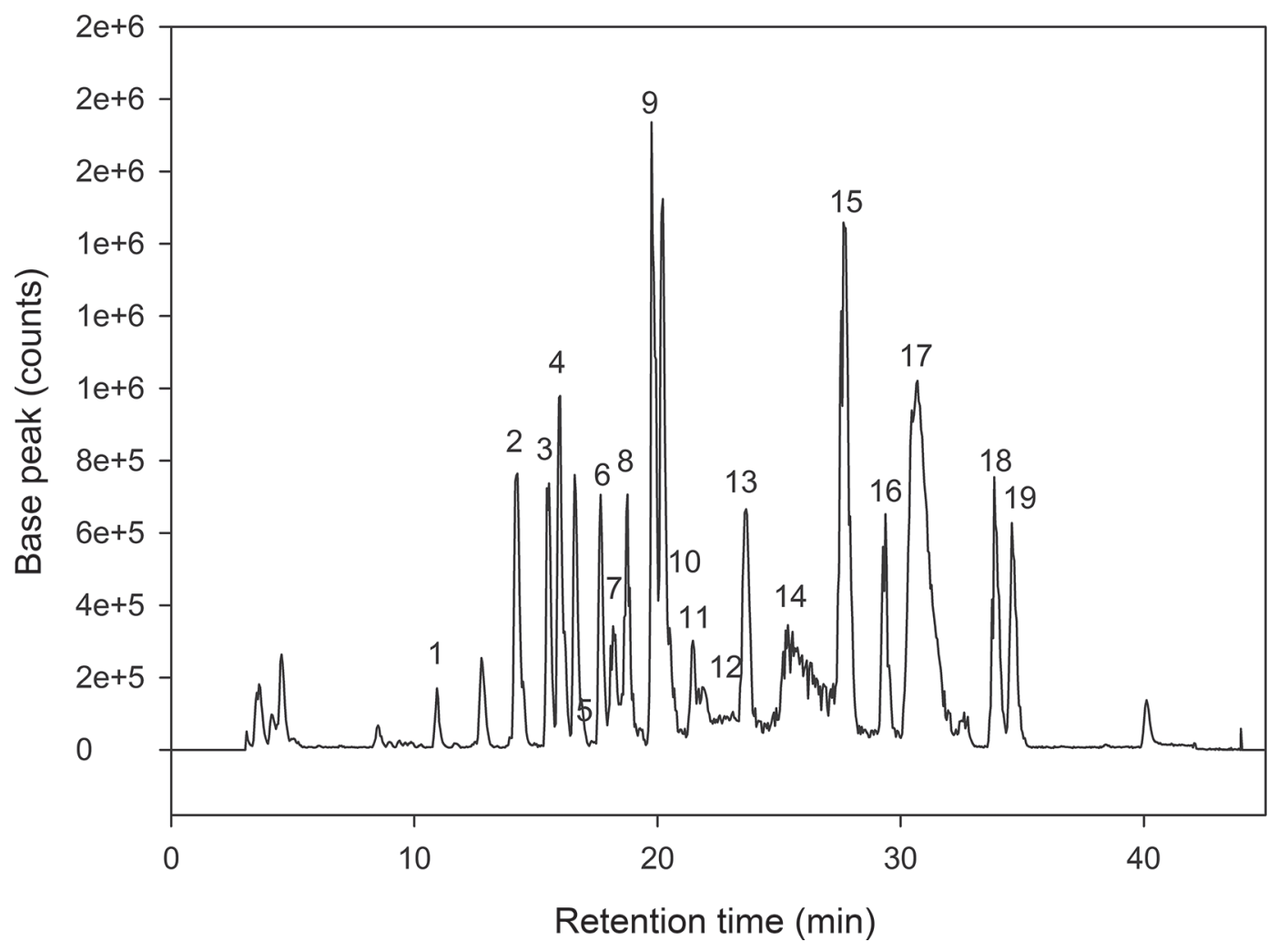

Figure 1. Liquid chromatography-MS profile of Prolyve $\beta$-CN hydrolysate (Lyven, Colombelles, France). Visible peaks of the main fragments (Table 1) are numbered 1 to 19 in the chromatograms. 
GCTTCCCAGAATCAA and GGGGATCACCAATGTGAGACCA for BMPrII (NM_080407).

Statistical analyses were carried out using Prism 4-7 (Graphpad Software, San Diego, CA). Results are expressed as mean \pm SEM. Differences were considered statistically significant for $P<0.05$.

We first analyzed the effect of $\beta$-CN hydrolysate on neuronal growth parameters in primary cultures of ENS. In untreated control conditions, enteric neurons were regrouped in ganglion-like structures interconnected by long neuronal processes (Figure 2A). Whereas no obvious changes were observed after treatment with the native $\beta-\mathrm{CN}$ or with the P-hydrolysate, the network formed by neurites appeared much denser when cells were treated with the T-hydrolysate (Figure 2, A-D). After $48 \mathrm{~h}$ of treatment, the area covered by NF165immunoreactive neurites was increased by $1.7 \pm 0.1$ fold after treatment with T-hydrolysate in comparison to untreated control $(\mathrm{n}=3-7)$. Similar results were observed after $96 \mathrm{~h}$ of treatment, as the area covered by NF165-immunoreactive neurites was significantly increased by $2.0 \pm 0.3$ fold in comparison to control (Figure 2, A-D, M). Furthermore, the number of ganglionic structures was increased $1.9 \pm 0.3$ fold after treatment with T-hydrolysate in comparison to untreated control (Figure $2 \mathrm{~N}$ ), whereas the mean size of these ganglia was significantly reduced to $46.4 \pm 7.5 \%$ of those observed under control conditions (Figure 2O).

Distribution pattern of EGC was similarly altered after treatment with T-hydrolysate (Figure 2, E-H). Glial bodies further appeared more differentiated, presenting sharper processes than in control conditions (Figure 2, I-L). Expression of the glial marker glial fibrillary acidic protein was significantly increased by $3.6 \pm 1.0$ fold, in comparison to control after $48 \mathrm{~h}$ of treatment with hydrolysate, and still showed a tendency to be increased after $96 \mathrm{~h}$ as assessed by quantitative PCR (Figure 3A), whereas expression of $\mathrm{S} 100 \beta$ remained unchanged (data not shown). Neither native $\beta-\mathrm{CN}$ nor the control P-hydrolysate significantly affected these parameters. Despite these important modifications, $\beta-\mathrm{CN}$ and bioactive hydrolysate had only limited effect on enteric neuron and EGC numbers, as enteric neurons were present in numbers comparable to control $(105.1 \pm 18.0 \%$ of control, $\mathrm{n}=6)$, whereas EGC numbers show a tendency to be increased $(113.5 \pm 6.582 \%$ of control, $\mathrm{n}=5$ ).

Both BMP2 and BMP4 signaling pathways are main regulators of ENS gangliogenesis (Fu et al., 2006; Chalazonitis and Kessler, 2012). Therefore, we evaluated the effect of treatment with $\beta$-CN hydrolysates on the mRNA expression of BMP2 and BMP4. Expression

Table 1. Identified peptides in the $\beta$-CN hydrolysate generated with the serine alkaline protease Prolyve 1000 (Lyven, Colombelles, France)

\begin{tabular}{llr}
\hline Peak $^{1}$ & Sequence $^{2}$ & Molecular mass, MH+ (Da) \\
\hline 1 & EAMAPK & 646.1 \\
2 & KKIEKF & 792.2 \\
3 & KAVPYPQ & 802.1 \\
4 & RDMPIQ & 759.0 \\
5 & SQSKVLPVPQK & $1,210.2$ \\
6 & TDVENL & 690.0 \\
& KKIEKFQSEEQQTEDELQDK & $2,689.5$ \\
7 & KVLPVPQ & 780.1 \\
8 & SQSKVLPVPQ & $1,082.2$ \\
9 & KAVPYPQRDMPIQ & $1,542.4$ \\
10 & KVLPVPQKAVPYPQ & $1,563.5$ \\
& SQSKVLPVPQKAVPYPQ & $1,865.5$ \\
11 & TLTDVENL & 904.1 \\
& MHQPHQPLPPTVM & $1,512.2$ \\
12 & SQSKVLPVPEKAVPYPQRDMPIQ & $2,607.4$ \\
13 & VYPFPGPIHN & $1,140.1$ \\
14 & VYPFPGPIPN & $1,100.1$ \\
& MHQPHQPLPPTVMFPPQ & $1,981.3$ \\
& KAVPYPQRDMPIQAF & $1,760.4$ \\
15 & SWMHQPHQPLPPTVMFPPQ & $1,128.1$ \\
16 & HLPLPL & 689.1 \\
& HLPLPLLQ & 930.2 \\
17 & SQSKVLPVPEKAVPYPQRDMPIQAF & $2,825.8$ \\
18 & HKEMPFPKYPVEPF & $1,745.4$ \\
19 & QEPVLGPVRGPFPIIV & $1,717.4$ \\
\hline
\end{tabular}

${ }^{1}$ Peak numbers refer to HPLC chromatograms in Figure 1.

${ }^{2}$ Peptide sequences identified with Proteome Discoverer 1.4 (Thermo Scientific Inc., San Jose, CA). Bold letters

$=$ main component of the peak. 

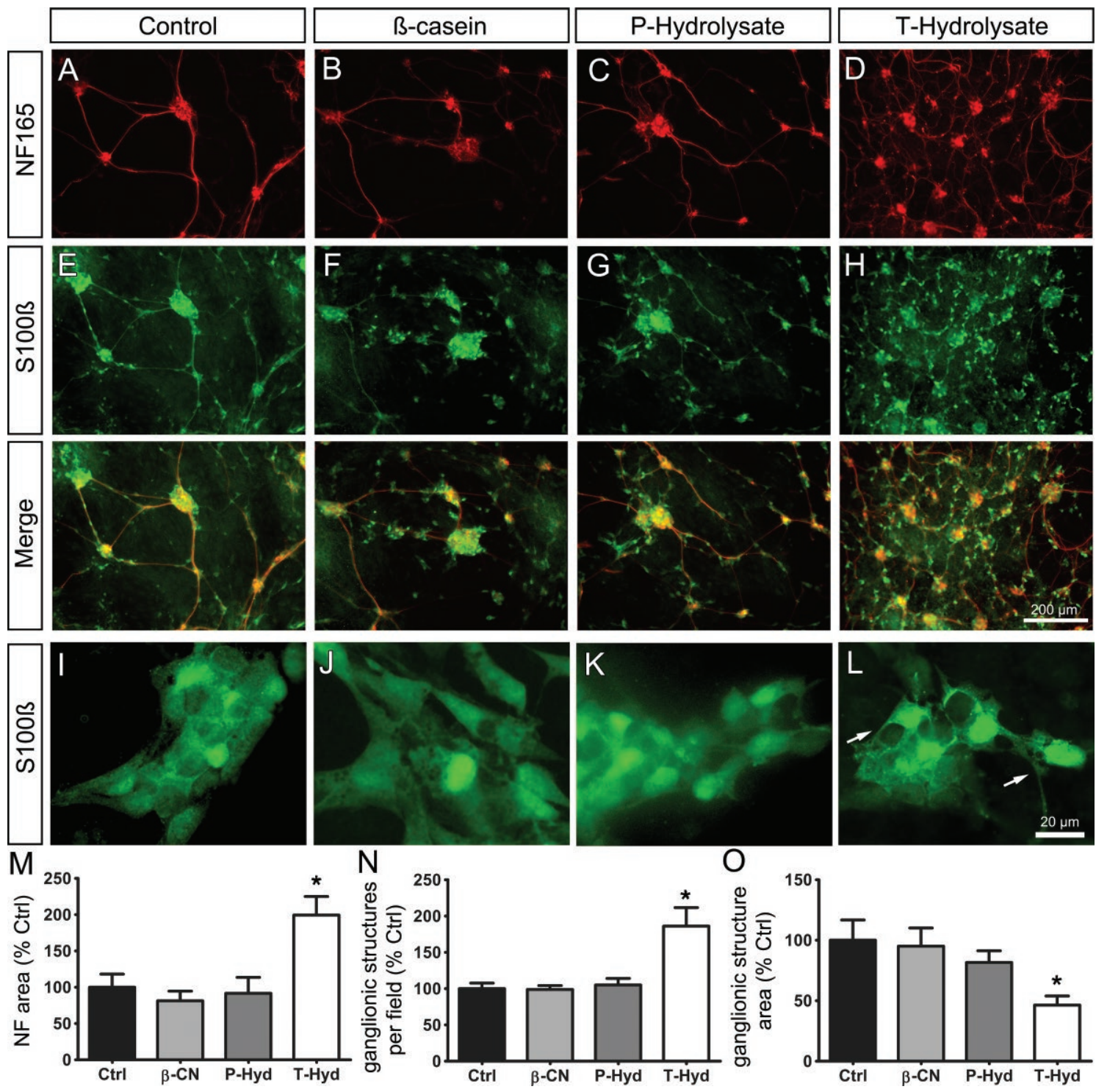

Figure 2. Bioactive bovine $\beta$-CN hydrolysate is neurotrophic for the enteric nervous system (ENS). Immunohistochemistry for the neurofilament marker NF165 (A-D) and the glial marker S1003 (E-L) were performed on primary cultures of ENS in control condition (A, E, I) or after treatment with native $\beta-\mathrm{CN}(1 \mathrm{mg} / \mathrm{mL}$; B, F, J), Prolyve hydrolysate (Lyven, Colombelles, France; P-hydrolysate, $1 \mathrm{mg} / \mathrm{mL}$; C, G, K), or tryptic hydrolysate (T-hydrolysate, $1 \mathrm{mg} / \mathrm{mL} ; \mathrm{D}, \mathrm{G}, \mathrm{L}$ ) for $96 \mathrm{~h}$. Scale bars, A-H $=200 \mu \mathrm{m}, \mathrm{I}-\mathrm{L}=20 \mu \mathrm{m}$. Treatment with T-hydrolysate induces morphological modifications of enteric glial processes (arrows). Quantification of the surface covered by neurofilament staining per field $(\mathrm{M} ; \mathrm{n}=5-7)$, number of ganglionic structures per field $(\mathrm{N} ; \mathrm{n}=6-8)$, and mean size of ganglionic structures $(\mathrm{O} ; \mathrm{n}=5-7)$ were measured. Results are means \pm SEM. Analysis of variance followed by Tukey's post-tests $(* P<0.05)$. Ctrl $=$ control; $\beta$-CN $=$ native $\beta$-casein; P-Hyd $=$ Prolyve hydrolysate; T-Hyd = tryptic hydrolysate. Color version available online.

of BMP2 mRNA was significantly increased by $2.5 \pm$ 0.4 fold after $48 \mathrm{~h}$ of treatment with T-hydrolysate in comparison to controls (Figure 3, C), and still showed a tendency to increase after $96 \mathrm{~h}$ of treatment (Figure 3, D). Expression of BMP4 mRNA expression was significantly reduced to $0.6 \pm 0.1$ fold of control level after $48 \mathrm{~h}$ and returned to levels comparable to control after $96 \mathrm{~h}$ of treatment with T-hydrolysate (Figure $3, \mathrm{E}-\mathrm{F})$, whereas neither native $\beta-\mathrm{CN}$ nor the control P-hydrolysate modulated the expression of BMP2 or
BMP4. No changes in expression of the mRNA of the $\mathrm{BMP}$ receptors BMPrIa, BMPrIb, and BMPrII were observed (data not show). To follow the BMP pathway, we assessed for the activation of their downstream effectors Smad 1/5. Phosphorylated forms of Smad1/5 (P-Smad1/5) were clearly detected within $\mathrm{HuC} / \mathrm{D}$ positive neurons, but also in the smooth muscle cells present in the culture (Figure 3, G-J). Interestingly, PSmad1/5 signal intensity was slightly but significantly decreased to $84.7 \pm 3.8 \%$ of control in $\mathrm{HuC} / \mathrm{D}$-positive 

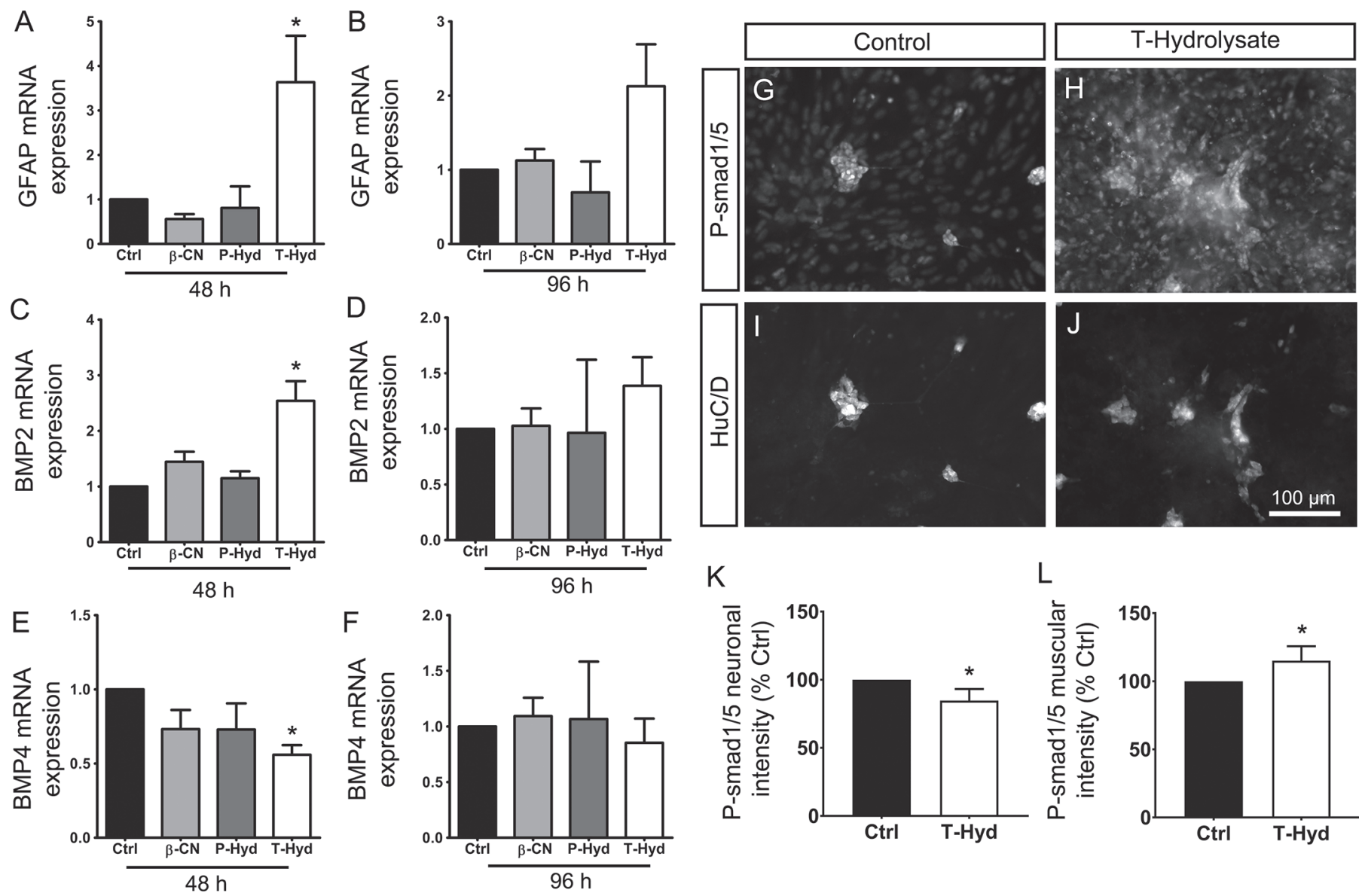

$\mathrm{K}$

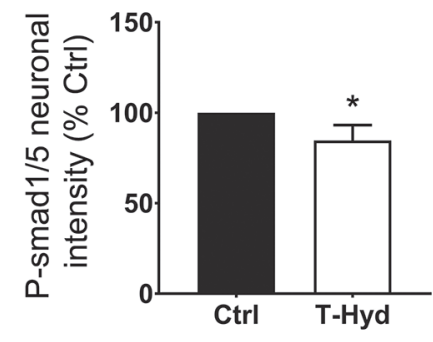

$\mathrm{L}$

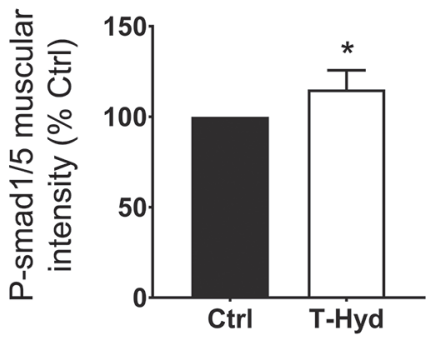

Figure 3. Bioactive bovine $\beta-\mathrm{CN}$ hydrolysate modulates bone morphogenetic proteins (BMP) expression. Expression analysis of glial fibrillary acidic protein (GFAP; A-B), BMP2 (C-D), BMP4 (E-F), mRNA from enteric nervous system (ENS) culture in control condition (Ctr) or after treatment with native $\beta-\mathrm{CN}(1 \mathrm{mg} / \mathrm{mL})$, Prolyve hydrolysate (Lyven, Colombelles, France; $1 \mathrm{mg} / \mathrm{mL}$; P-Hyd), or bioactive tryptic hydrolysate $(1 \mathrm{mg} / \mathrm{mL}$; T-Hyd) for 48 (A, C, E) or $96 \mathrm{~h}(\mathrm{~B}, \mathrm{D}, \mathrm{F})$ was determined using quantitative PCR. Co-stainings for P-Smad1/5 (G-H) and the pan-neuronal marker $\mathrm{HuC} / \mathrm{D}(\mathrm{I}-\mathrm{J})$ were performed on untreated primary cultures of ENS $(\mathrm{G}, \mathrm{I})$ or cultures treated with the tryptic hydrolysate $(1 \mathrm{mg} / \mathrm{mL}, \mathrm{H}, \mathrm{J}$, T-Hydrolysate) for $48 \mathrm{~h}$. Phospho $(\mathrm{P})$-Smad1/5 signal intensity was measured in neurons (K) or in the surrounding smooth muscle cells (L). A-F = ANOVA followed by Tukey's post-tests $\left(\mathrm{n}=3-20 ;{ }^{*} P<0.05\right) ; \mathrm{K}-\mathrm{L}=\mathrm{Student} t$-test $\left(\mathrm{n}=4-5 ;{ }^{*} P<0.05\right)$. Results are means \pm SEM.

neurons (Figure $3 \mathrm{~K}$ ) and increased to $115.1 \pm 4.7 \%$ of control level in the surrounding smooth muscle cells (Figure $3 \mathrm{~L}$ ).

Many studies have shown that milk-derived bioactive peptides may stimulate newborn development (Raikos and Dassios, 2014). Although casein-derived peptides can directly influence gut and even brain development (Kost et al., 2009), very limited studies have assessed the effect of milk-derived hydrolysate on the ENS. Most studies are focused on the regulation of intestinal motility by the opioid agonist casomorphin (Dalziel et al., 2014). To the best of our knowledge, our study represents the first description of a casein-derived hydrolysate presenting neurotrophic activity for the ENS.

Importantly, these effects were specific for this $\mathrm{T}$ hydrolysate, as the control proteolytic P-hydrolysate, presenting a different peptides profile, did not exhibit similar properties in our assays. This indicates that the effects mediated by the T-hydrolysate probably rely on specific bioactive properties of this hydrolysate rather than on potential nutritive effects. Further work will be required to identify the bioactive peptides responsible of these effects within this fraction.

Bioactive peptides are naturally released from native casein after digestion and can be detected in the blood circulation after ingestion (Boutrou et al., 2013; Chabance et al., 1998). This indicates that milkderived bioactive peptides, such as those present in the T-hydrolysate used in our study, are at least in part resistant to proteolysis during digestion and can further cross the intestinal epithelial and blood or gut barriers. Because of their close proximity to blood vessels and intestinal epithelial cells within the intestinal wall, enteric neurons and EGC are also sensible 
to nutritional factors (Neunlist and Schemann, 2014), highly suggesting that such bioactive peptides could also reach the ENS microenvironment and the enteric neuro-musculature in vivo. Whether such milk-derived peptides sustain intestinal maturation processes under physiological conditions is still not clear. As supplementation of infant formula with milk-derived bioactive peptides has been proposed, our study provides novel proof of concept that casein-derived bioactive hydrolysate can modulate growth parameters of the enteric neuro-musculature in a complex in vitro system and emphasize the need to further characterize the effect of such bioactive peptides in vivo.

Development and maturation of the enteric neuromusculature rely on complex regulatory pathways. Among them, we showed that the T-hydrolysate used in our study modulates the expression of BMP2 and 4 and the activation of their downstream effectors Smad1/5 in enteric neurons, as well as in the surrounding smooth muscles cells.

In vivo expression of BMP2 and 4 coincides with ENS maturation, where they regulate multiple aspects of intestinal muscle, enteric neurons, and EGC development in a concentration-dependent manner (De Santa Barbara et al., 2005; Chalazonitis and Kessler, 2012). More particularly, BMP2 and BMP4 regulate the response of enteric progenitor cells to neurotrophic factors, stimulate enteric gangliogenesis, but also induce apoptosis of enteric neurons at highest concentrations (Chalazonitis et al., 2004; Goldstein et al., 2005; Chalazonitis and Kessler, 2012). Therefore we propose that the phenotype observed in our study may result in large part from the unbalanced regulation of BMP (i.e., decreased expression of BMP4 and increased expression of BMP2, by the T-hydrolysate), and this regulation might involve both direct and indirect smooth musclemediated, regulatory mechanisms.

The hydrolysate used in our study was previously shown to inhibit tumor necrosis factor- $\alpha$-induced nuclear factor- $\kappa \mathrm{B}(\mathbf{N F} \boldsymbol{} \mathbf{B})$ pathway in HEK cells (Altmann et al., 2016). In the ENS, NFKB activation has been shown to stimulate neurite outgrowth through both cell and non-cell autonomous pathways (Gougeon et al., 2013; Zhang et al., 2014). Alternatively, at least a whey-protein hydrolysate has been shown to mitigate the activation of toll-like receptors (TLR; Iskandar et al., 2013), which are also involved in the control of ENS development (Anitha et al., 2012). Interestingly both TLR and NFKB have been identified has upstream regulators of the BMP/Smad signaling pathway (Feng et al., 2003; Su et al., 2011; Huang et al., 2014), suggesting that a cross-regulation of BMP through TLR or NFkB could also be involved in our model. Further work is needed to fully demonstrate the involvement of the BMP/Smad pathway in the phenotype observed here and to determine if other factors might also be involved in this regulation. More particularly, further characterization of the bioactive peptides within the T-hydrolysate used in our study, and characterization of the cellular receptors and molecular mechanisms involved, will require further intensive investigations.

Finally, our data demonstrate the potential to use casein-derived bioactive hydrolysate to target ENS development. This may have important implications for the treatment of gastrointestinal disorders, particularly in infants. Further studies are needed to fully decipher the mechanism of action of this hydrolysate and to further determine its potential effect on brain and gastrointestinal-tract maturation in vivo.

\section{ACKNOWLEDGMENTS}

This work and F. Cossais were supported by the German Federal Ministry for Education and Research (BMBF) as part of the competence network "FoCus - Food Chain Plus". The authors sincerely thank S. Kaschner for expert technical assistance and K. Knappstein (Max Rubner Institute, Department of Safety and Quality of Milk and Fish Products, Kiel, Germany) for providing access to the microscope.

\section{REFERENCES}

Altmann, K., A. Wutkowski, M. Klempt, I. Clawin-Rädecker, H. Meisel, and P. C. Lorenzen. 2016. Generation and identification of anti-inflammatory peptides from bovine $\beta$-casein using enzyme preparations from cod and hog. J. Sci. Food Agric. 96:868-877. https://doi.org/10.1002/jsfa.7159.

Anitha, M., M. Vijay-Kumar, S. V. Sitaraman, A. T. Gewirtz, and S. Srinivasan. 2012. Gut microbial products regulate murine gastrointestinal motility via Toll-like receptor 4 signaling. Gastroenterology 143:1006-16.e4. https://doi.org/10.1053/j.gastro.2012.06.034.

Boutrou, R., C. Gaudichon, D. Dupont, J. Jardin, G. Airinei, A. Marsset-Baglieri, R. Benamouzig, D. Tomé, and J. Leonil. 2013. Sequential release of milk protein-derived bioactive peptides in the jejunum in healthy humans. Am. J. Clin. Nutr. 97:1314-1323. https://doi.org/10.3945/ajcn.112.055202.

Chabance, B., P. Marteau, J. C. Rambaud, D. Migliore-Samour, M. Boynard, P. Perrotin, R. Guillet, P. Jollès, and A. M. Fiat. 1998. Casein peptide release and passage to the blood in humans during digestion of milk or yogurt. Biochimie 80:155-165.

Chalazonitis, A., F. D'Autréaux, U. Guha, T. D. Pham, C. Faure, J. J. Chen, D. Roman, L. Kan, T. P. Rothman, J. A. Kessler, and M. D. Gershon. 2004. Bone morphogenetic protein-2 and -4 limit the number of enteric neurons but promote development of a TrkCexpressing neurotrophin-3-dependent subset. J. Neurosci. 24:42664282. https://doi.org/10.1523/JNEUROSCI.3688-03.2004.

Chalazonitis, A., and J. A. Kessler. 2012. Pleiotropic effects of the bone morphogenetic proteins on development of the enteric nervous system. Dev. Neurobiol. 72:843-856. https://doi.org/10.1002/ dneu.22002.

Chevalier, J., P. Derkinderen, P. Gomes, R. Thinard, P. Naveilhan, P. Vanden Berghe, and M. Neunlist. 2008. Activity-dependent regulation of tyrosine hydroxylase expression in the enteric nervous system. J. Physiol. 586:1963-1975. https://doi.org/10.1113/ jphysiol.2007.149815. 
Cossais, F., T. Durand, J. Chevalier, M. Boudaud, L. Kermarrec, P. Aubert, I. Neveu, P. Naveilhan, and M. Neunlist. 2016. Postnatal development of the myenteric glial network and its modulation by butyrate. Am. J. Physiol. Gastrointest. Liver Physiol. 310:G941G951. https://doi.org/10.1152/ajpgi.00232.2015.

Dalziel, J. E., N. J. Spencer, K. E. Dunstan, A. T. Lynch, N. W. Haggarty, P. K. Gopal, and N. C. Roy. 2014. An in vitro rat model of colonic motility to determine the effect of $\beta$-casomorphin- 5 on propagating contractions. Food Funct. 5:2768-2774. https://doi. org/10.1039/c4fo00193a.

De Santa Barbara, P., J. Williams, A. M. Goldstein, A. M. Doyle, C. Nielsen, S. Winfield, S. Faure, and D. J. Roberts. 2005. Bone morphogenetic protein signaling pathway plays multiple roles during gastrointestinal tract development. Dev. Dyn. 234:312-322. https://doi.org/10.1002/dvdy.20554.

de Vries, P., R. Soret, E. Suply, Y. Heloury, and M. Neunlist. 2010. Postnatal development of myenteric neurochemical phenotype and impact on neuromuscular transmission in the rat colon. Am. J. Physiol. Gastrointest. Liver Physiol. 299:G539-G547. https://doi. org/10.1152/ajpgi.00092.2010.

Feng, J. Q., L. Xing, J.-H. Zhang, M. Zhao, D. Horn, J. Chan, B. F. Boyce, S. E. Harris, G. R. Mundy, and D. Chen. 2003. NFkappaB specifically activates BMP-2 gene expression in growth plate chondrocytes in vivo and in a chondrocyte cell line in vitro. J. Biol. Chem. 278:29130-29135. https://doi.org/10.1074/jbc. M212296200.

Fichter, M., M. Klotz, D. L. Hirschberg, B. Waldura, O. Schofer, S. Ehnert, L. K. Schwarz, C. Van Ginneken, and K.-H. Schäfer. 2011. Breast milk contains relevant neurotrophic factors and cytokines for enteric nervous system development. Mol. Nutr. Food Res. 55:1592-1596. https://doi.org/10.1002/mnfr.201100124.

Fu, M., B. P. S. Vohra, D. Wind, and R. O. Heuckeroth. 2006. BMP signaling regulates murine enteric nervous system precursor migration, neurite fasciculation, and patterning via altered Ncam1 polysialic acid addition. Dev. Biol. 299:137-150. https://doi. org/10.1016/j.ydbio.2006.07.016.

Furness, J. B. 2012. The enteric nervous system and neurogastroenterology. Nat. Rev. Gastroenterol. Hepatol. 9:286-294. https://doi. org/10.1038/nrgastro.2012.32.

Goldstein, A. M., K. C. Brewer, A. M. Doyle, N. Nagy, and D. J. Roberts. 2005. BMP signaling is necessary for neural crest cell migration and ganglion formation in the enteric nervous system. Mech. Dev. 122:821-833. https://doi.org/10.1016/j.mod.2005.03.003.

Gougeon, P.-Y., S. Lourenssen, T. Y. Han, D. G. Nair, M. J. Ropeleski, and M. G. Blennerhassett. 2013. The pro-inflammatory cytokines IL-1 $\beta$ and TNF $\alpha$ are neurotrophic for enteric neurons. J. Neurosci. 33:3339-3351. https://doi.org/10.1523/ JNEUROSCI.3564-12.2013.

Huang, R.-L., Y. Yuan, G.-M. Zou, G. Liu, J. Tu, and Q. Li. 2014 LPS-stimulated inflammatory environment inhibits BMP-2-induced osteoblastic differentiation through crosstalk between TLR4/MyD88/NF- $\kappa B$ and BMP/Smad signaling. Stem Cells Dev. 23:277-289. https://doi.org/10.1089/scd.2013.0345.
Iskandar, M. M., N. Dauletbaev, S. Kubow, N. Mawji, and L. C. Lands. 2013. Whey protein hydrolysates decrease IL-8 secretion in lipopolysaccharide (LPS)-stimulated respiratory epithelial cells by affecting LPS binding to Toll-like receptor 4. Br. J. Nutr. 110:5868. https://doi.org/10.1017/S0007114512004655.

Kost, N. V, O. Y. Sokolov, O. B. Kurasova, A. D. Dmitriev, J. N. Tarakanova, M. V Gabaeva, Y. A. Zolotarev, A. K. Dadayan, S. A. Grachev, E. V. Korneeva, I. G. Mikheeva, and A. A. Zozulya. 2009. Beta-casomorphins-7 in infants on different type of feeding and different levels of psychomotor development. Peptides 30:1854-1860. https://doi.org/10.1016/j.peptides.2009.06.025.

Krüger, K., F. Cossais, H. Neve, and M. Klempt. 2014. Titanium dioxide nanoparticles activate IL8-related inflammatory pathways in human colonic epithelial Caco-2 cells. J. Nanopart. Res. 16:2402. https://doi.org/10.1007/s11051-014-2402-6.

Lönnerdal, B. 2014. Infant formula and infant nutrition: bioactive proteins of human milk and implications for composition of infant formulas. Am. J. Clin. Nutr. 99:712S-717S. https://doi.org/10.3945/ ajcn.113.071993.

Malinowski, J., M. Klempt, I. Clawin-Rädecker, P. C. Lorenzen, and H. Meisel. 2014. Identification of a NFkB inhibitory peptide from tryptic $\beta$-casein hydrolysate. Food Chem. 165:129-133. https:// doi.org/10.1016/j.foodchem.2014.05.075.

Meisel, H. 2005. Biochemical properties of peptides encrypted in bovine milk proteins. Curr. Med. Chem. 12:1905-1919.

Neunlist, M., and M. Schemann. 2014. Nutrient-induced changes in the phenotype and function of the enteric nervous system. J. Physiol. 592:2959-2965. https://doi.org/10.1113/jphysiol.2014.272948.

Neunlist, M., L. Van Landeghem, M. M. Mahé, P. Derkinderen, S. B. des Varannes, and M. Rolli-Derkinderen. 2013. The digestive neuronal-glial-epithelial unit: A new actor in gut health and disease. Nat. Rev. Gastroenterol. Hepatol. 10:90-100. https://doi. org/10.1038/nrgastro.2012.221.

Raikos, V., and T. Dassios. 2014. Health-promoting properties of bioactive peptides derived from milk proteins in infant food: A review. Dairy Sci. Technol. 94:91-101. https://doi.org/10.1007/ s13594-013-0152-3.

Su, X., L. Ao, Y. Shi, T. R. Johnson, D. A. Fullerton, and X. Meng. 2011. Oxidized low density lipoprotein induces bone morphogenetic protein-2 in coronary artery endothelial cells via Toll-like receptors 2 and 4. J. Biol. Chem. 286:12213-12220. https://doi. org/10.1074/jbc.M110.214619.

Suply, E., P. de Vries, R. Soret, F. Cossais, and M. Neunlist. 2012. Butyrate enemas enhance both cholinergic and nitrergic phenotype of myenteric neurons and neuromuscular transmission in newborn rat colon. Am. J. Physiol. Gastrointest. Liver Physiol. 302:G1373G1380. https://doi.org/10.1152/ajpgi.00338.2011.

Zhang, Y., D. Bitner, A. A. Pontes Filho, F. Li, S. Liu, H. Wang, F. Yang, S. Adhikari, J. Gordon, S. Srinivasan, and W. Hu. 2014. Expression and function of NIK- and IKK2-binding protein (NIBP) in mouse enteric nervous system. Neurogastroenterol. Motil. 26:77-97. https://doi.org/10.1111/nmo.12234. 